\title{
LITERATURE ON ANIMAL PSYCHOLOGY PUBLISHED IN FRANCE DURING THE YEAR 1910
}

\author{
GEORGES BOHN \\ Paris, France
}

The French literature for rgro is not extensive, and deals almost wholly with invertebrates. There is a very marked tendency to study the reactions of animals from the chemical point of view. The hypothesis that sensibility is a function of the rate of chemical reactions is in my opinion likely to prove very fertile

In the series of publications, numbers $28,28,30,31,32$, in the bibliography, I have applied the concepts of physical chemistry to the study of the sensibility of the lower animals. I have recognized that such sensibility varies within rather wide limits; thus the Veritillum (Veritillum cynomorium) is at times absolutely insensible to light and to mechanical stimuli, while at other times its sensibility is very great; sometimes merely touching the tentacle of one polyp makes the whole colony retract. I observed lessened sensibility especially under the three following conditions: prolonged illumination; repeated stimulation; continued activity. Light, when it has acted a certain length of time on the organism, is a desensibilisator. An actinian exposed to strong illumination finally becontes insensitive to light and expands: the process is more rapid the stronger the light and the higher the temperature. Consequently the reactions of many beach-dwelling animals towards evening differ from the morning reactions, under the same conditions of illumination and surroundings. On the other hand planarians, living under the stones in brooks or streams, quickly lose sensibility even to diffuse light: it is possible to note the rise of threshold from hour to hour. The whole process is what would happen if light destroyed a certain active substance in the organism.

In general, mechanical shocks heighten sensibility; but if they are repeated a certain number of times the opposite effect is finally observed. Loss of sensibility under these conditions 
occurs sooner, the longer the exposure of the organism to light; in the morning shocks continue to heighten sensibility for a long time; in the erening they quickly produce a loss of sensibility. Under the influence of shocks, we should have exhaustion of certain active substances, but the organism is more richly supplied with these substances in the morning than in the evening.

I studied chemical, physical, and mechanical sensibilisators, but more particularly the last. I recognized among other points that one can modify the sensibility of an organism merely by changing its orientation to gravity: a molluse (Littorina) with its head downward has less visual sensibility than when it is moving with head upward. This would correspond to an altered distribution of active substances in the cells of the retina. I also observed an effect of increased sensibility as a result of increased surface of the body in animals whose bodies swell, for instance the Veritillum; and under the influence of increased pressure or of weights carried by the animal: ants with a load -are much more sensitive to light than those which carry nothing.

Finally, I pointed out that all these variations in sensibility may be taken account of in the study of tropisms.

Matisse ${ }^{5}$ worked with the following species of animals: Sagartia parasitica, Asterias rubens, Nereilepas furcata, Arenicola piscatorum, Sipunculus nudus, Haminea navicula, Cardinm edule, Pectunculus glycimeris, Sepia officinalis, Eupagurus bernhardus.

He took proper account in his experiments of the oscillations in sensibility and motor activity at different times. Cold more or less rapidly and completely suspends the sensibility and motor activity of organisms: between $10^{\circ}$ and $2^{\circ} \mathrm{C}$. most of the animals studied became insensible and inert. The functions of nutritive life (respiration and circulation), however, were continued with sufficient intensity. In the cuttlefish the case is different: as the life of response diminishes the functions of vegetative life weaken; death occurred at $7^{\circ} \mathrm{C}$. by respiratory paralysis accompanying locomotor paralysis. The action of cold is in general reversible; the same is not true of the action of high temperatures, which often produce the same effects as cold. However, differences may be observed: at $34^{\circ} \mathrm{C}$., Sagartia dies in a few hours, in a state of contraction; at $2^{\circ}$, the anemone expands, loses sensibility, but remains alive. All these facts 
are easily explained by invoking the conception of speed of chemical reaction.

Rose ${ }^{\circ}$ has studied tropisms to light and heat and the corresponding differential sensibility in Daphnia. Among other results he verified the observation of Loeb that weak $(\mathrm{n} / 500)$ mineral acids are sensibilisators. He verified also a law which I have pointed out: any sudden variation in the light produces a vertical displacement in the animals: if the intensity is suddenly increased they sink, if it is diminished they rise. He recognized that Weber's Law would be applicable in this connection, and he has extended to warmth the results which have been found for light. The notion of differential sensibility based on certain laws has shown itself fertile here.

Drzewina ${ }^{38}$ has studied the reactions to light of Clibanarius misanthropus Risso. At Arcachon, on the Atlantic, she noted a curious parallelism between the fortnightly movements of the tide and the periodicity of variations in the sign of phototropism. But at Banyuls, on the Mediterranean, she always found marked positive phototropism, a fact which is not surprising in view of the different ethological conditions. Howerer, starting with the hypothesis that heliotropic sensibility is a function of the speed of chemical reactions, D. succeeded in modifying the sign of the reactions to light. If the water in the vessels is daily changed, the phototropism remains positive, but it becomes negative in unrenewed water. The addition of sea salt ( $\mathrm{I}$ to roo) raises the sensibility to light and neutralises the influence of impure water. With carbonic acid (ro parts of Seltzer water to roo) change in the sign of the phototropism results at once. Individuals long exposed to light and those subjected to prolonged shocks finally move towards the shade.

Further, Drzewina ${ }^{37}$ has made an elegant application of the associative method to the study of sensations in these crabs. She put naked hermit crabs near shells hermetically closed with cork; the animals at once fastened upon them, trying to tear off the cork. Their efforts were in vain, and in time they appeared more and more indifferent to the shells; six or eight days after the beginning of the experiment, when they encountered them, they continued on their course, or even pushed the shells away. Now if at this point shells were introduced similarly stopped with cork but of a different shape, the behavior of the animals 
changed at once. As soon as a crab encountered a shell he carried it off, and for five or ten minutes persistently explored it in all directions and tried to pull off the cork. This fact proves not only that new associations can be formed in these crabs, and that consequently they are susceptible of training. but also that they are capable of apprehending form differences by means of tactile sensations.

Two important memoirs relating to the experimental analysis of instincts, by Faurot and by Cornetz, have appeared.

Faurot ${ }^{41}$ first studies the adaptive conformation of the hermit crab and the deformity and growth of Adamsia palliata in symbiosis with Eupagurus Prideauxi. The development of the actinian forms in a certain sense part of that of the crab The association of Pagurus striatus and Sagartia parasitica presents quite difierent features: it does not begin until the two organisms have almost reached their normal growth, and it is always possible for them to live separated from each other. F. investigates the mode of formation of the two sorts of association; symbiosis and mutualism. He brought together naked Eupagurus Pridcanxi, others lodged in shells furnished with Adamsias, empty shells with Adamsias on them, and Adamsias either isolated from their shells or adherent to some support. In general the crabs recognized the Adamsias by means of their tactile sensibility, which is extraordinarily developed, they immediately carried of an Adamsia palliata, but not Sagartia parasitica, Heliactis bellis, or Corynactis viridis. Crabs provided with Adamsias, put near naked shells, dud not exchange their shelter for the latter. If they were despoiled of their associates, they fell upon a naked shell with as much eagerness as if it had been an Adamsia. If, however, the separation were of less recent date, the attracting reaction produced by contact with a naked shell was much weaker. In the search for shells and actinians sight plays a certain rôle, the risual field would be bounded by a regular circle whose radius is the length of the antennae plus four to six centimeters.

F. describes a Pagurus striatus detaching a Sagartia parasitica from the bottom of the aquarium: the claws of the crab grasp the actinian especially in the region near the edges of the pedal disk. This region gradually diminishes in diameter and the disk detaches itself from the support, the tentacles of the actinian 
then fasten on the shell, then the column bends in such a way that the pedal disk approaches the shell. After this kind of somersault, the actinian fastens itself on the shell occupied by the crab. Six or seven may attach themselves successively upon the same shell.

Cornetz ${ }^{88, ~}{ }^{87}$ has observed the following species of ants in Algeria: Messor barbarus and its variety sancta, A phaenogaster testaceopilosa, Myrmecocystus cataglyphis bicolor, Tapinoma erraticum nigerrimum, Tetramorium caespitum punicum, Pheidole pallidula. He collected with great care about two hundred paths made by ants travelling alone. The return to the nest seems to be a function of the outward journey; if an ant is captured at the mouth of the nest and carefully transported several meters away, she is unable to return, while the home journey is rapid and easy when the explorer has herself made the outward trip. However, the two paths, outward and homeward, are never superposed; the sequence of movements and attitudes is quite different on the return journey; an ant who crosses her trace left on the outward trip does not stop and does not follow it. The new and important fact brought to light by C. is the faculty possessed by the exploring ant of maintaining her course in a given direction. The insect adopts her direction on leaving the nest and keeps it as well on the return journey as on the outward trip, always resuming it after the path has been interrupted either by her own researches or by the intervention of the observer. The ant suddenly stops, makes a turn, a loop, a double loop, a complicated search in the grass; or perhaps, threatened, she flees in one direction or another, but soon after, she replaces the axis of her body in the direction adopted on leaving the nest, behaving somewhat like a compass. The error in degrees which she makes in thus replacing herself is usually very slight. Ten or twelve such intervals of searching about may intervene, but the course remains governed by the direction taken at starting. On the outward course the road is interrupted, but the same orientation constantly reappears; on the return, it is still preserved. Thus the ant is brought back to a point not far from her nest; to find it, she makes the windings described by Turner. Sometimes the phenomena are a little more complicated; the insect outward bound adopts successively two directions, often 
at right angles to each other, and on the return retraces them successively in inverse order.

This work of C.'s, as he expresses it, " undermines the theory" which attributes the return to the nest to muscular memory." The sequence of movements on the return journey is often quite different from that of the movements performed on the outward course. When there is a change of direction, it cannot be attributed to muscular memory: if, at such a moment. the ant is on a movable support, and the support is turned through a certain angle, the ant, disturbed, after having made various movements, takes the same direction that she would have taken without the interruption. In any case. there are two kinds of muscular memory : memory of a sequence of movements. and memory of the total work accomplished. According to $\mathrm{C}$., the first does not exist in ants, and if we admit the second, it is of a very crude sort, and cannot explain the return to the nest. We have, in fine, memory of one or of several successive directions, which it seems to me cannot be explained except by associative memory - acting on the sensations furnished by certain landmarks. We are thus brought back to the conception maintained by the American investigator Turner.

Many observations have been made on the habits of insects and birds. As regards the latter, a certain number of studies are reported in the Revue francaise d'ornithologie; the subjects are the maternal instinct, nest-building, and migration. Among the best observers of insects I may cite Ch. Ferton and E. Roubaud.

Ferton ${ }^{86}$ among other things describes certain peculiarities of nest-building (closure by partitions of parchment, building a barricade of sand) and gives numerous details regarding the prey of the Hymenoptera. We may note also certain curious observations on the methods used by Pompilidae to paralyze spiders, and on "attention in the return to the-nest."

The Synagris are solitary wasps belonging to the family of the Eumenides and living exclusively in Africa. By the study of three species, Roubaud ${ }^{70,}{ }^{80}$ has been able to show instinct evolving from the "once-for all" type of provisioning the nest usual with the Eumenides, towards the continuous supplying of food and daily care of offspring which is found in social wasps. 
Thus in a single genus we find the principal stages leading from the primitive instinct of solitary wasps to the far more highly developed instinct of social wasps.

It is to be regretted that the French have almost wholly neglected experimental researches on the higher animals, which have given such fine results in America. The only method used on the higher animals is that of training.

The paper by Hachet-Souplet is a lecture summarizing the ideas already expounded by the author. In particular, H.-S. reports experiments where he accustomed birds to react in a definite way to a definite variation in illumination. He explains what he calls the law of recurrence, one of the laws of sensory association, and accounts by its means for the supposed rational foresight of birds. Intelligence does not come in until there is a possibility of "persuasion" (see also C.r. Acad. Sci., CL, pp. 238 and 735 ).

Besides these accounts of personal investigations, we have to note a certain number of discussions of the problems of comparative psychology, such as "La genèse des instincts esclavagistes et parasitaires chez les Fourmis, " by Piéron 108, "L'orientation lointaine," by Thauziès ${ }^{20}$ " "L'etude objective des phenomènes cérébraux," by Bohn 2, "Le dressage des animaux," by Drzewina ", and finally, a book by Piéron ${ }^{17}$ on "L'évolution de la mémoire." This book, published in the Bibliothêque de philosophie scientifique, comprises two parts, the one dealing with animals and the other with man. In the former, the author after having indicated the relations of the phenomena of inorganic memory, of hysteresis, for example, with those of psychic memory, studies rhythmic persistances (plant rhythms, animal rhythms, organic rhythms), and dwells at length on the discussion of facts and experiments regarding animal memory, which he classes under three heads: adaptive memory, acquisition of habits, sensory memory. These rubrics correspond to the different methods of research on animal memory, such as the study of the modification of reactions under the influence of repeated stimulation, the study of the reproduction of movements, and that of the recognition of images. The author devotes only a few lines to the work of the school of Pawlow, although it is generally considered of great importance for the study of associative memory in the higher vertebrates. He insists on the distinction between 
motor memory and sensory memory, and considers muscular memory to be involved in the return of insects to the nest. In the second part of the book the author discusses the aspects and limits of human memory, what its disturbances consist in and what its progress may be. He attempts to prove that man is not a creature essentially different from the animals, an opinion which seems to be still quite common in philosophic circles. 